\title{
Implicações das oscilações climáticas do Quaternário tardio na evolução da fisionomia da vegetação do semiárido do Nordeste Setentrional
}

\author{
Implications of late Quaternary climatic oscillations on the evolution of vegetation \\ physiognomy in the semi-arid region of the septentrional Northern
}

\author{
OLIVEIRA $^{1}$, A. M.; AMORIM², R. F.; $\operatorname{COSTA}^{3}$, D. F. S.
}

alissongeoliveira@gmail.com

\begin{abstract}
Resumo
A cobertura vegetal de Caatinga na porção semiárida do Nordeste sententrional do Brasil é fisionomicamente caracterizada por ser arbustiva, com indivíduos espaçados entre si e apresentando um estrato herbáceo bem definido, sendo este estrato vegetal composto por plantas anuais. Devido à intensa alteração da cobertura vegetal, não há fragmentos ou formações vegetais remanescentes précolonização, dificultando a iniciativa de inferências acerca de uma fisionomia vegetal da Caatinga antes da chagada dos colonos. No contexto de estudos paleoambientais e dinâmica fisionômica e biogeográfica no Quaternário, a cobertura vegetal da área carece de informações, e aproveitando esta lacuna, este trabalho objetiva realizar uma discussão sobre a evolução paleoambiental para o Nordeste Setentrional. As interpretações das condições paleoambientais do semiárido do Nordeste Setentrional permitem inferir que a fisionomia da Caatinga oscilou entre savanas com condições de manter uma megafauna pleistocênica e fisionomias florestais entre 42 mil anos A.P. e 11.800 anos A.P. Sua atual fisionomia é resultados de ações humanas que começaram no século VXII.
\end{abstract}

Palavras-chave: Caatinga, Quaternário tardio, Savana.

\begin{abstract}
The vegetative cover of the Caatinga in the semi-arid region of the septentrional Northern Brazil is physiognomically characterized by being shrub, with individuals spaced apart and presenting a well defined herbaceous stratum, being this plant stratum composed of annual plants. Due to the intense alteration of the vegetation cover, there are no fragments or plant formations remaining pre-colonization, making it difficult to infer inferences about a plant physiognomy of the Caatinga before the arrival of the settlers. In the context of paleoenvironmental studies and physiognomic and biogeographic dynamics in the Quaternary, the vegetation cover of the area lacks information, and taking advantage of this lacuna, this work aims to conduct a discussion on paleoenvironmental evolution for the septentrional Northern Brazil. The interpretations of the paleoenvironmental conditions of the semi-arid region of the septentrional Northern Brazil allow us to infer that the Caatinga physiognomy oscillated between savannas capable of maintaining a pleistocene megafauna and forest physiognomies between 42,000 years BP and 11,800 years BP. Its present physiognomy is the result of human actions that began in the century VXII.
\end{abstract}

Keywords: Caatinga, Late Quaternary, Savannah.

\section{INTRODUÇÃO}

A cobertura vegetal de Caatinga na porção semiárida do Nordeste setentrional do Brasil (sobretudo a PB, o RN e o CE) é fisionomicamente caracterizada por ser arbustiva, com indivíduos

${ }^{I}$ Alisson Medeiros de Oliveira, Programa de Pós-Graduação em Geografia, Universidade Federal do Rio Grande do Norte, Natal$R N$, Brasil

${ }^{2}$ Rodrigo Freitas de Amorim, Departamento de Geografia, Universidade Federal do Rio Grande do Norte, Natal-RN, Brasil

${ }^{3}$ Diógenes Félix da Silva Costa, Departamento de Geografia, Universidade Federal do Rio Grande do Norte, Caicó-RN, Brasil 
espaçados entre si e apresentando um estrato herbáceo bem definido, sendo este estrato vegetal composto por plantas anuais (AMORIM; SAMPAIO; ARAÚJO, 2005; AMORIM; SAMPAIO; ARAÚJO, 2009; SANTANA et al., 2011; NETO; FERNANDES, 2016), o que a faz ser classificada como Savana-Estépica Gramíneo-Lenhosa (VELOSO, 1991; IBGE, 1992; IBGE, 2012). Esta fisionomia está presente principalmente na Depressão Sertaneja e em encostas rochosas, onde predominam Neossolos Litólicos e Luvissolos Crômicos.

Do ponto de vista geomorfológico, o relevo da região apresenta formas suavemente onduladas e bastante dissecadas pertencentes à Depressão Sertaneja, sendo a monotonia da paisagem quebrada por maciços ígneos, inselbergs, que criam formas de relevo destoantes do contexto regional (MAIA; AMARAL; PRAXEDES, 2013; MAIA; BEZERRA, 2014). A cobertura vegetal presente nos maciços e inselbergs difere florística e fisionomicamente da que recobre as áreas mais depressivas (RODAL; BARBOSA; THOMAS, 2008; NETO; SILVA, 2012), mudança essa especialmente relacionada aos controles do relevo. No contexto dessas diferenças, é cada vez mais recorrente a ideia de que a atual fisionomia da Caatinga da região seja resultado do intenso uso de seus recursos lenhosos desde o início da ocupação pelos colonos, entre os séculos XVIII e XIV, sendo que esta utilização culminou com áreas de desertificação (NETO; SILVA, 2012).

Devido à intensa alteração da cobertura vegetal, não há fragmentos ou formações vegetais, intactas, remanescentes da pré-colonização, dificultando a iniciativa de inferências acerca de uma fisionomia vegetal da Caatinga antes da chagada dos colonos. Além disso, em virtude sobreutilização dos componentes vegetais de Caatinga, a erosão dos solos da região foi amplificada (SANTOS et al., 2000), gerando ambientes com relações edafológicas que permitem a colonização apenas por vegetais de comunidades secundárias, sobretudo de espécies indicadoras de ambientes ecologicamente estressados (SANTANA et al., 2011).

Para a área em questão, estudos paleoambientais são escassos (e.g. MUTZENBERG, 2007; KINOSHITA et al., 2005; DANTAS et al., 2013). Bem como na Região Nordeste, há falta de dados e estudos sobre a dinâmica da vegetação de Caatinga ao longo do Pleistoceno/Holoceno (BEHLING et al., 2000). No contexto de estudos paleoambientais e dinâmica fisionômica da cobertura vegetal na área de estudo durante o Quaternário tardio, a área carece de informações, e aproveitando esta lacuna, este trabalho objetiva realizar uma discussão sobre a evolução da dinâmica fisionômica da vegetação no Semiárido do Nordeste Setentrional. 


\section{OCILAÇÕES PALEOCLIMÁTICAS E DINÂMICA BIOGEOGRÁFICA NEOTROPICAL NO QUATERNÁRIO}

As oscilações climáticas no período Quaternário têm singular importância na compreensão Paleoambiental, e tais mudanças climáticas influenciaram a dinâmica Paleoambiental em todo o planeta (ADAMS; MASLIN; THOMAS, 1999; PETIT et al., 1999). Desde o último estágio interglacial semelhante ao atual (interglacial Eemian), que ocorreu entre 140 mil e 120 mil anos A.P., oscilações climáticas têm ocorrido, ora apresentando temperaturas mais elevadas do que a atual, ora com temperaturas mais baixas (ADAMS; MASLIN; THOMAS, 1999), além do Último Máximo Glacial - UMG, com seu fim entre 20 mil anos - 10 mil anos A.P. (SUGUIO, 2010). A Figura 01 destaca alguns dos principais eventos ocorridos no Pleistoceno e Holoceno, as épocas mais importantes para a compreensão Paleoambiental e Paleobiogeográfica.

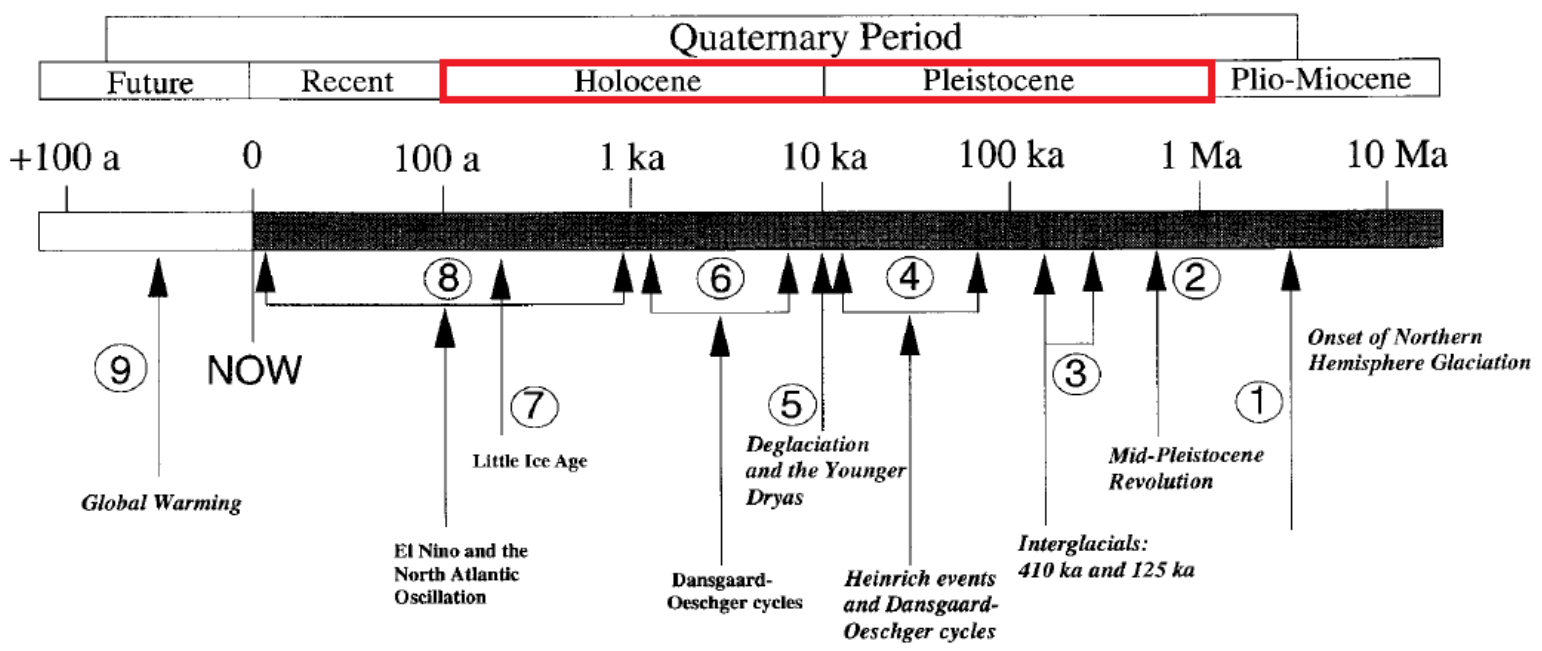

Figura 01: Principais eventos e oscilações climáticas ocorridas no Quaternário. Fonte: Adaptado de Adams; Maslin; Thomas, (1999).

Eventos com ciclicidade de curto prazo, especialmente na escala de $10^{2}$ produzem respostas significativas na vegetação e na remobilização dos mantos de intemperismo que recobrem as rochas (AMORIM et al. 2015). Se faz mister considerar que a atuação de paleo-ENOS provocando períodos secos mais intensos e longos que os atuais podem ser a chave para o entendimento da configuração atual da Caatinga na área de estudo, tendo em vista que intervalos com baixas precipitações podem ser significativos para diminuição de espécies arbóreas. Eventos como o Younger Dryas e a Pequena Idade do Gelo são exemplos de eventos de escalas de curto prazo que influenciaram a dinâmica fisionômica da vegetação da área de estudo (BEHLING et al., 2000; MUTZENBERG, 2007; AMORIM, 2015; AMORIM et al. 2015). 
No contexto da região biogeográfica Neotropical, as implicações do Quaternário são pesquisadas principalmente no que se refere à paleoclimas, paleoambientes e megafauna, sendo a região amazônica uma das áreas com vários estudos sobre a evolução geológica de ambientes quaternários. Em 1969, o biogeógrafo Jürgen Haffer identificou áreas de endemismo de aves em meio a florestas amazônica, e foi interpretado que durante o Pleistoceno os ecossistemas florestais se retraíram em manchas de vegetação onde as condições ambientais permitiram a permanência de espécies vegetais e animais (HAFFER, 1969). Essa dinâmica de retração de florestas é explicada pela hipótese dos Refúgios Pleistocênicos, a qual versa que durante as condições climáticas mais secas e frias que as atuais, as florestas tropicais retraíram, e como consequência, houve a expansão de savanas (AB’SÁBER, 1982; PRADO; GIBBS, 1993; BROWN; LOMOLINO, 2006).

Segundo Van Der Hammen; Absy (1994), o clima na Amazônia, durante o UMG, se caracterizou por ser mais seco e frio que as condições atuais, especialmente entre $22.000-11.000$ anos A.P. Nestas condições, a floresta amazônica ficou retida em refúgios (Figura 02), enquanto que formações vegetais de savanas se expandiram (HAFFER, 1969; AB'SÁBER, 1982; RIBEIRO, 2002). Apesar de bem difundida, a hipótese vem sendo contestada por novos dados paleoambientais (OLIVEIRA et al., 2014).

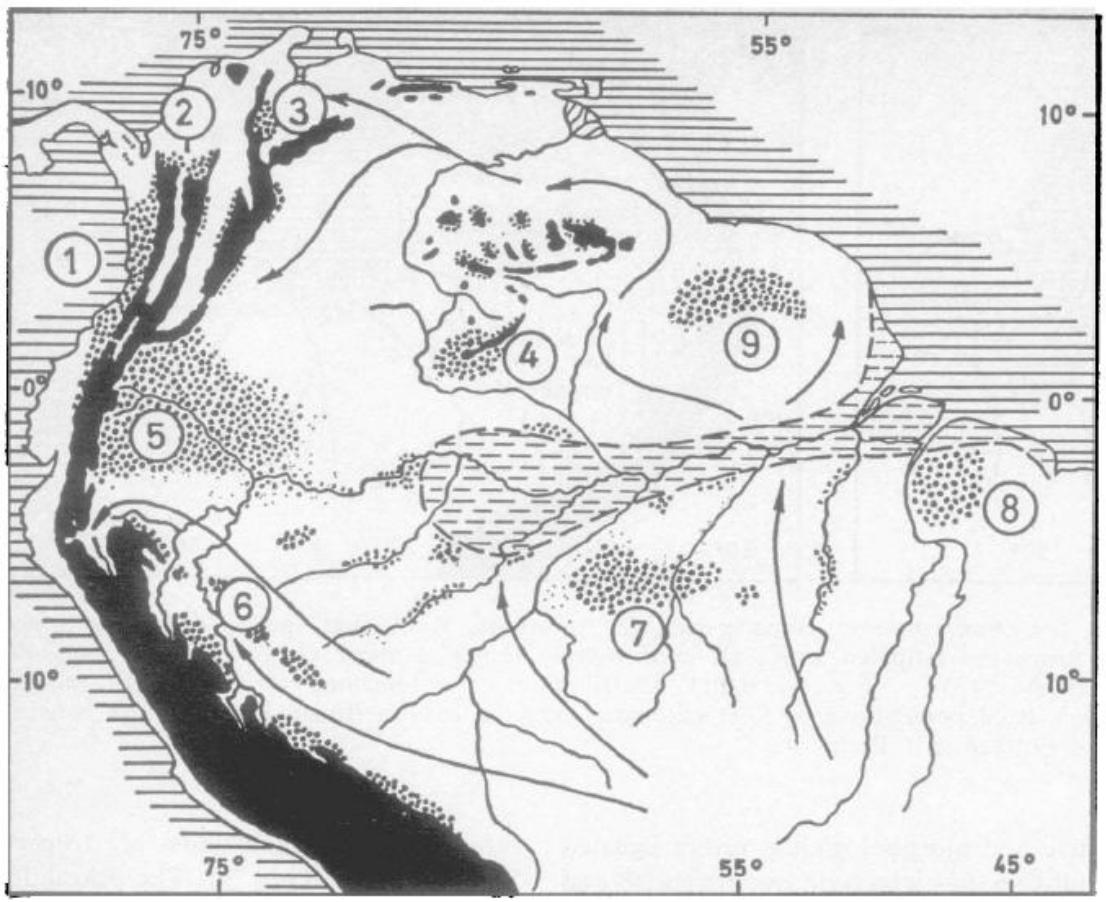

Figura 02: Refúgios identificados por Haffer (numerados de 1 a 9). Fonte: Haffer (1969).

Em resposta as condições climáticas mais frias e secas no UMG, os ecossistemas de savanas do Neotrópico experimentaram expansão em suas áreas de ocorrência (AB’SÁBER, 1982; 
PRADO; GIBBS, 1993). A expansão de tais fisionomias vegetais levou a hipótese de que os principais ecossistemas de savanas da América do Sul (Llanos, Chaco, Cerrado e Caatinga) formaram uma Floresta Tropical Sazonalmente Seca - FTSS (SDTF, sigla em inglês) que se distribuiu pelo leste, centro-sul, oeste e norte da América do Sul (Figura 03), essa hipótese recebe o nome de “Arco Pleistocênico" (PRADO; GIBBS, 1993; PENNINGTON; PRADO; PENDRY, 2000).

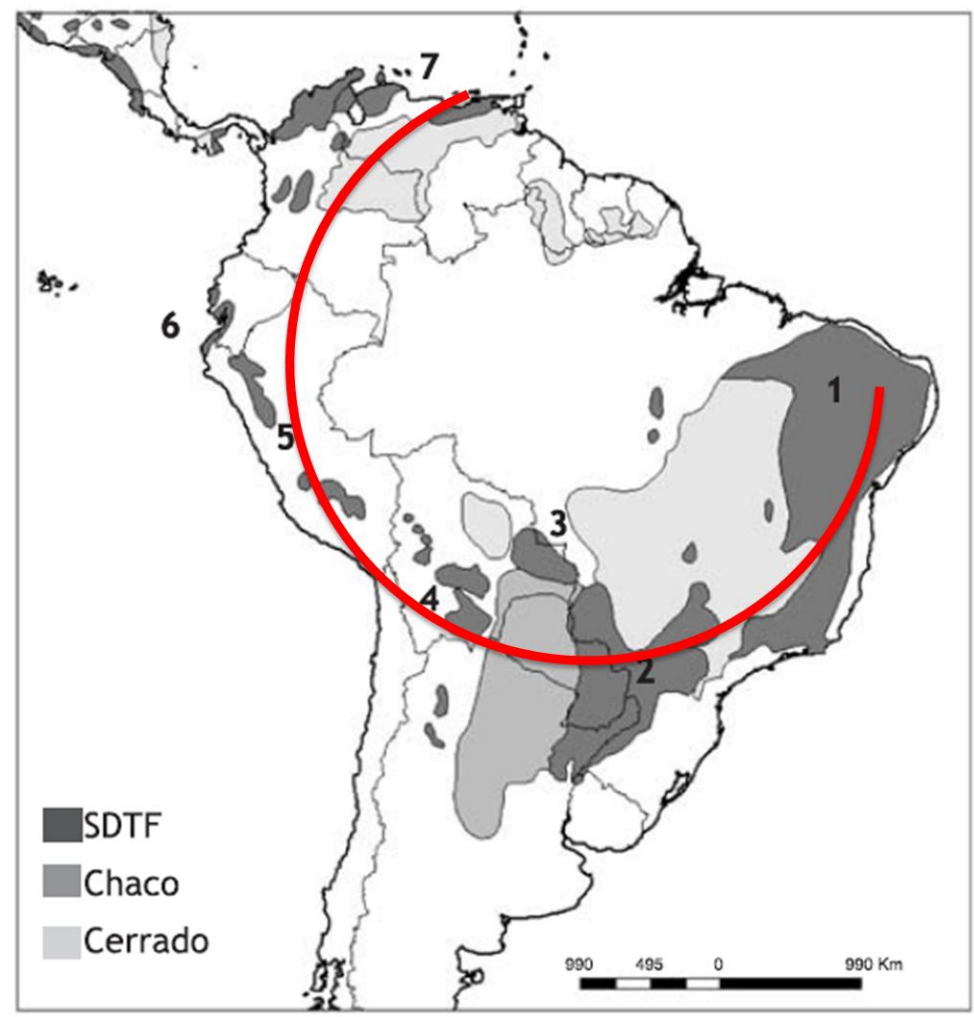

Figura 03: Ecossistemas de savanas da América do Sul, que no UMG, formaram a FTSS. Fonte: Adaptado de Pennington; Prado; Pendry (2000).

A Floresta Tropical Sazonalmente Seca teve seu apogeu em termos espaciais no UMG entre 18.000 e 12.000 anos A.P. (PRADO; GIBS, 1993), e permitiu que espécies dessa floresta se dispersassem pelo Neotrópico, explicando assim a ocorrência de diferentes espécies de distintos ambientes de savanas (e.g. Anadenanthera colubrina (Vellozo), Amburana cearensis (A. C. Smith) e Myracrodruon urundeuva (Allemão) (PRADO; GIBS, 1993; PENNINGTON; PRADO; PENDRY, 2000; PENNINGTON et al., 2004; CAETANO et al., 2008). No intuito de corroborar com a hipótese que as espécies se dispersaram pela América do Sul por meio da FTSS, foi realizado um estudo sobre a estrutura genética da Myracrodruon urundeuva (Allemão), com dados coletados em ambientes que formaram a FTSS. A pesquisa mostrou que o cloroplasto do vegetal investigado 
teve poucas mudanças (Figura 04), indicando pouco isolamento, o que significa dizer que a Myracrodruon urundeuva (Allemão) não colonizou o Neotrópico se dispersando por meio de savanas fragmentadas (o que implicaria em isolamento e mudanças na estrutura genética, ou até mesmo em especiação) (CAETANO et al., 2008).

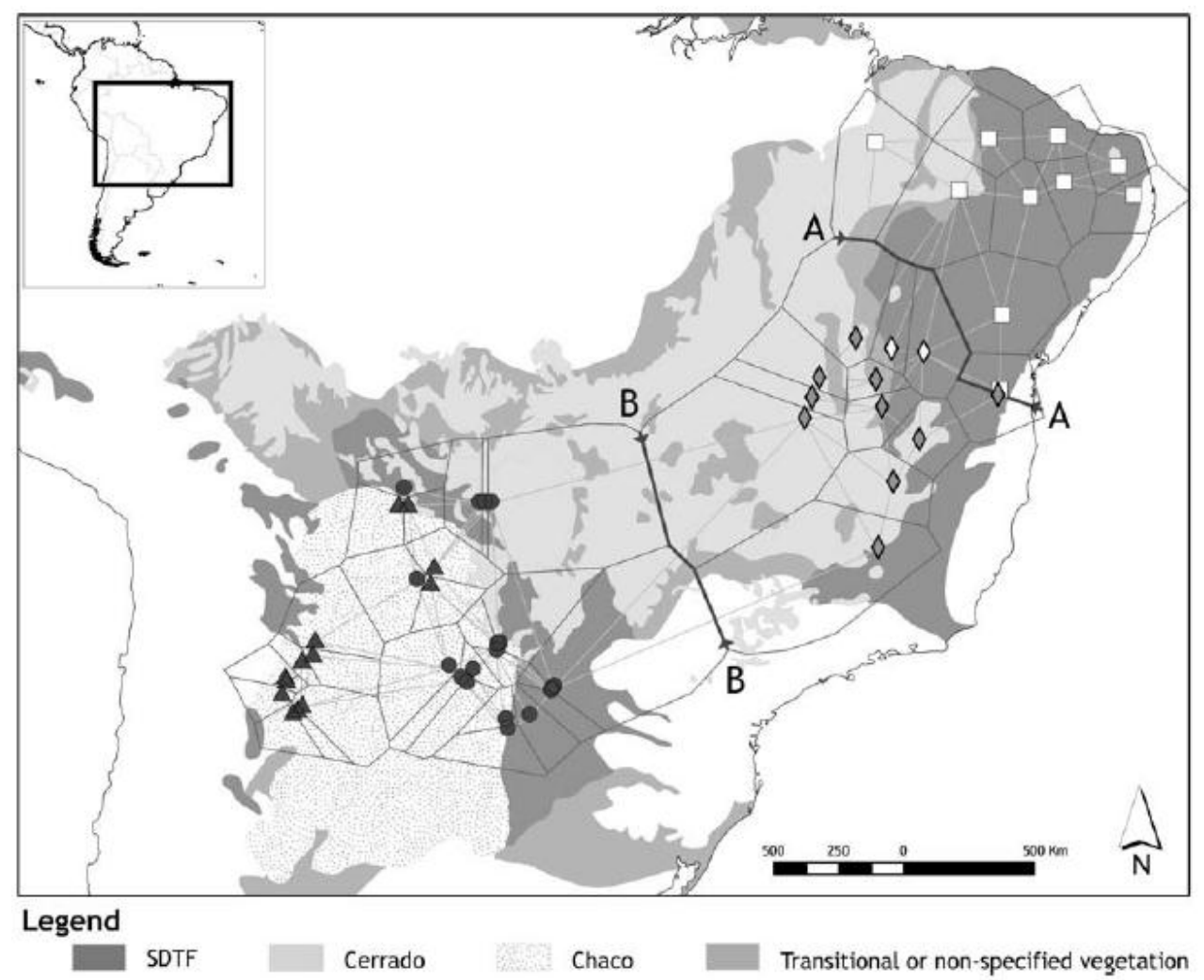

Figura 04: Agrupamentos das análises genéticas, sendo A e B grupos distintos. Fonte: Caetano et al (2008).

Atualmente, a Floresta Tropical Sazonalmente Seca está distribuída de forma disjunta pelo Neotrópico, sendo a Caatinga um bioma considerado uma dessas disjunções (PENNINGTON; PRADO; PENDRY, 2000; CAETANO et al., 2008). A FTSS fisionomicamente diferente das savanas, pois a primeira apresenta ecossistemas dominados por arvores e copa relativamente contínua (PENNINGTON; PRADO; PENDRY, 2000). Contudo, a Caatinga não vem sendo considerada uma FTSS, mas uma savana (VELOSO, 1991; IBGE, 1992; RODAL; BARBOSA; THOMAS, 2008; IBGE, 2012). É importante salientar que a Caatinga já foi bastante antropizada desde a ocupação deste bioma pelos colonos, sendo sua fisionomia atual decorrência da sua alteração. A seguir, a Figura 05 mostra três ambientes atuais de FTSS no Neotrópico. No que tange a ocorrência de paleofauna, Dantas et al (2013a) realizaram um estudo sobre o potencial de distribuição do Mastodonte pela América do Sul (Notiomastodon platensis (Ameghino, 1888)) (Figura 06). 

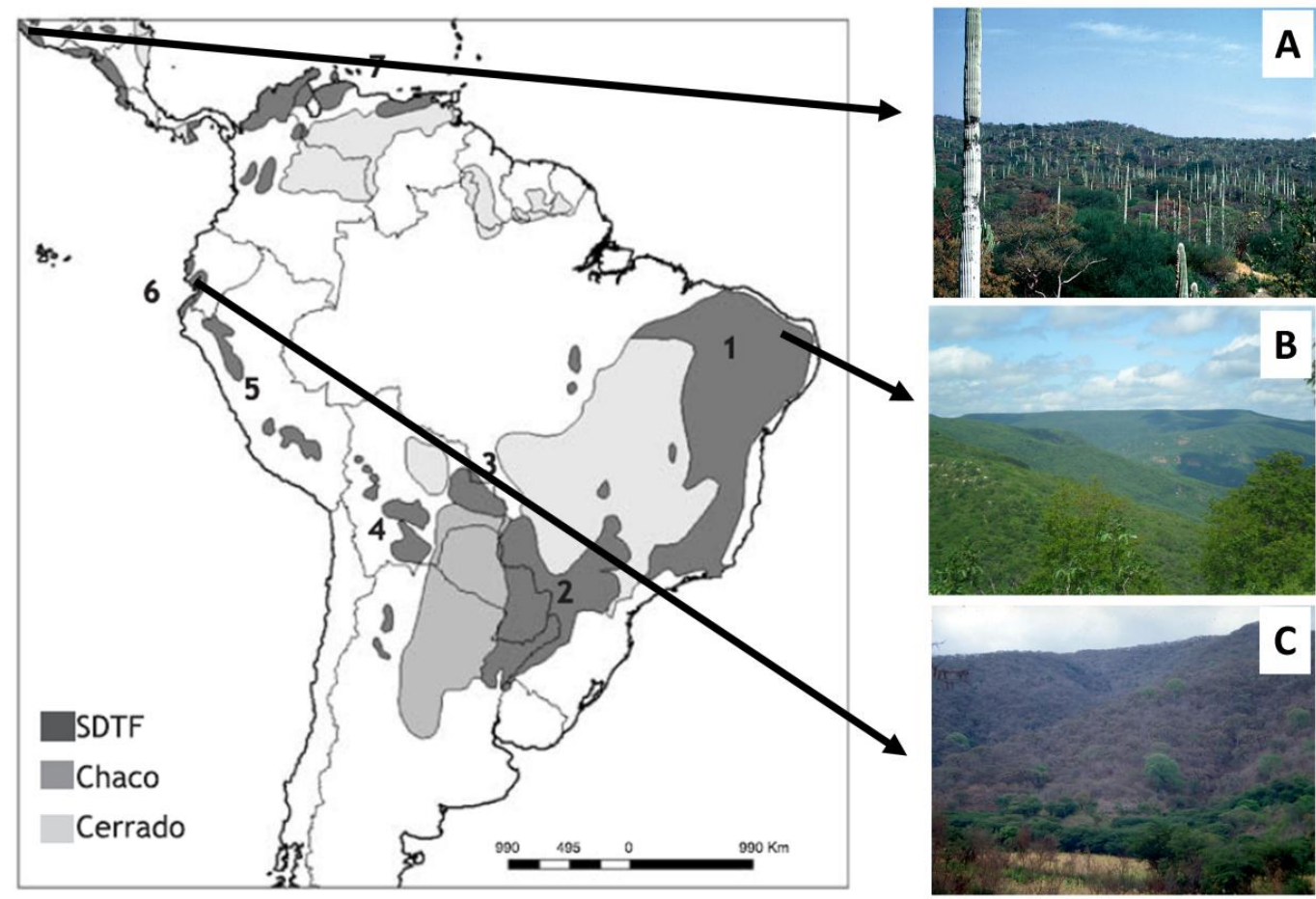

Figura 05: Atual FTSS no Neotrópico: Formações no México - A (PENNINGTON et al., 2004), Brasil - B (Acervo dos autores) e Equador - C (PENNINGTON et al., 2004). Fonte: Adaptado de Pennington; Prado; Pendry (2000) e Pennington et al (2004).

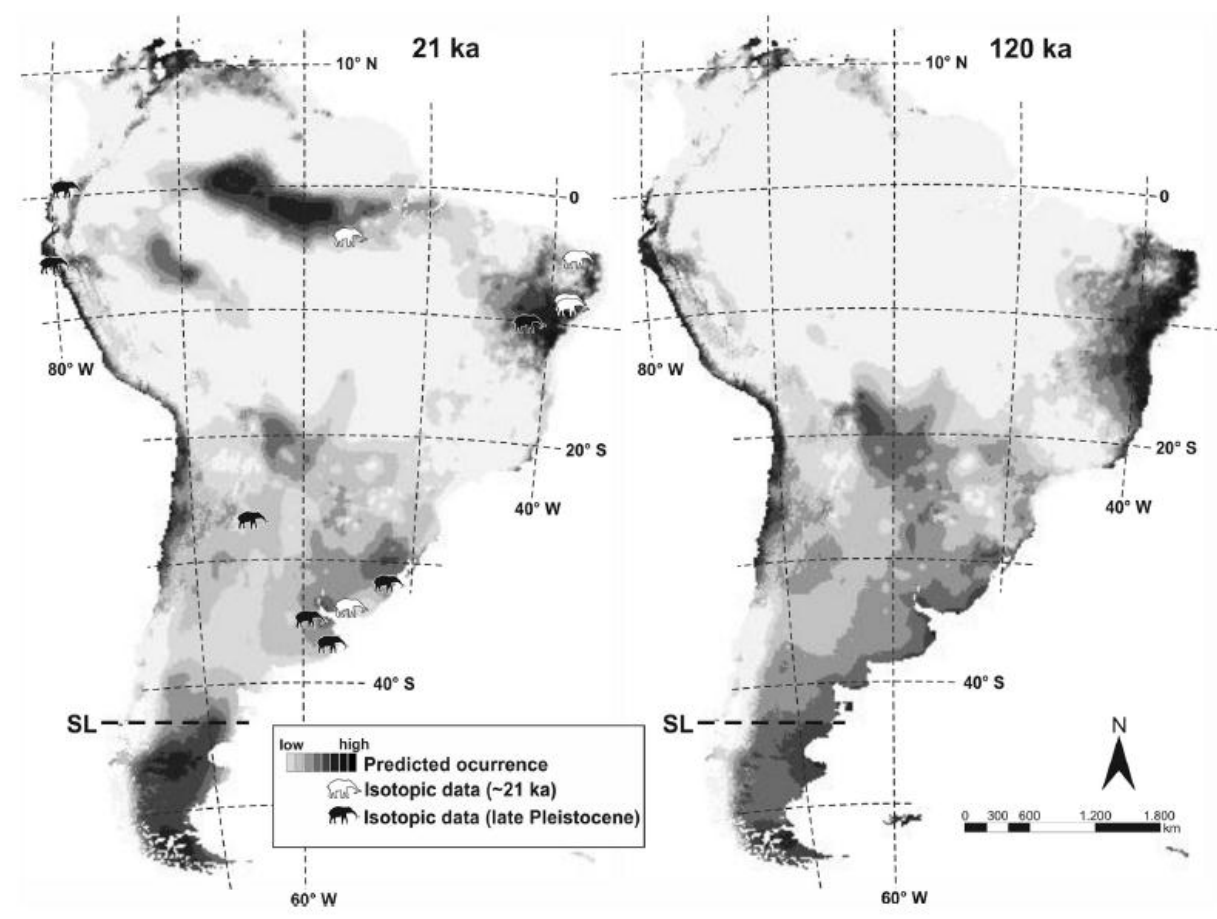

Figura 06: Potencial de distribuição do Notiomastodon platensis (Ameghino, 1888) para 120 mil anos A.P. e 21 mil anos A.P. Fonte: Dantas et al (2013a). 


\section{INFERÊNCIAS SOBRE A INFLUÊNCIA DO QUATERNÁRIO EM PALEOAMBIENTES DO SEMIÁRIDO DO NORDESTE SETENTRIONAL}

Para o semiárido do Nordeste Setentrional, há registros de Caatinga para 42.000 anos A.P., em datação realizada Behling et al. (2000) de uma amostra de sedimentos da plataforma continental (GeoB 3104-1), no litoral do Ceará. As condições climáticas interpretadas para 42.000 anos A.P. na amostra de sedimentos GeoB 3104-1 era de condições úmidas (a primeira de quatro fases úmidas para a amostra), porém de rápida duração (BEHLING et al., 2000). Esta interpretação climática dá base para uma possível fisionomia de savana para a Caatinga, mas com todos os estratos vegetais sendo bem mais desenvolvidos que os estratos atuais. É possível que este porte fisionômico de 42.000 anos A.P. tenha dado condições ambientais para o suporte de uma megafauna de ecossistemas de savanas, pois entre 35.000 e 25.000 anos A.P., condições úmidas (cerca de 33.000 anos A.P., ver Figura 07) podem ter influenciado para a formação (ou continuidade da fisionomia de savanas desde 42.000 anos A.P.) de savanas onde o Notiomastodon platensis (Ameghino, 1888) foi registrado na Paraíba, sendo seu fóssil datado de $30 \pm 5$ mil anos A.P. (KINOSHITA et al., 2005; DANTAS et al., 2013a).

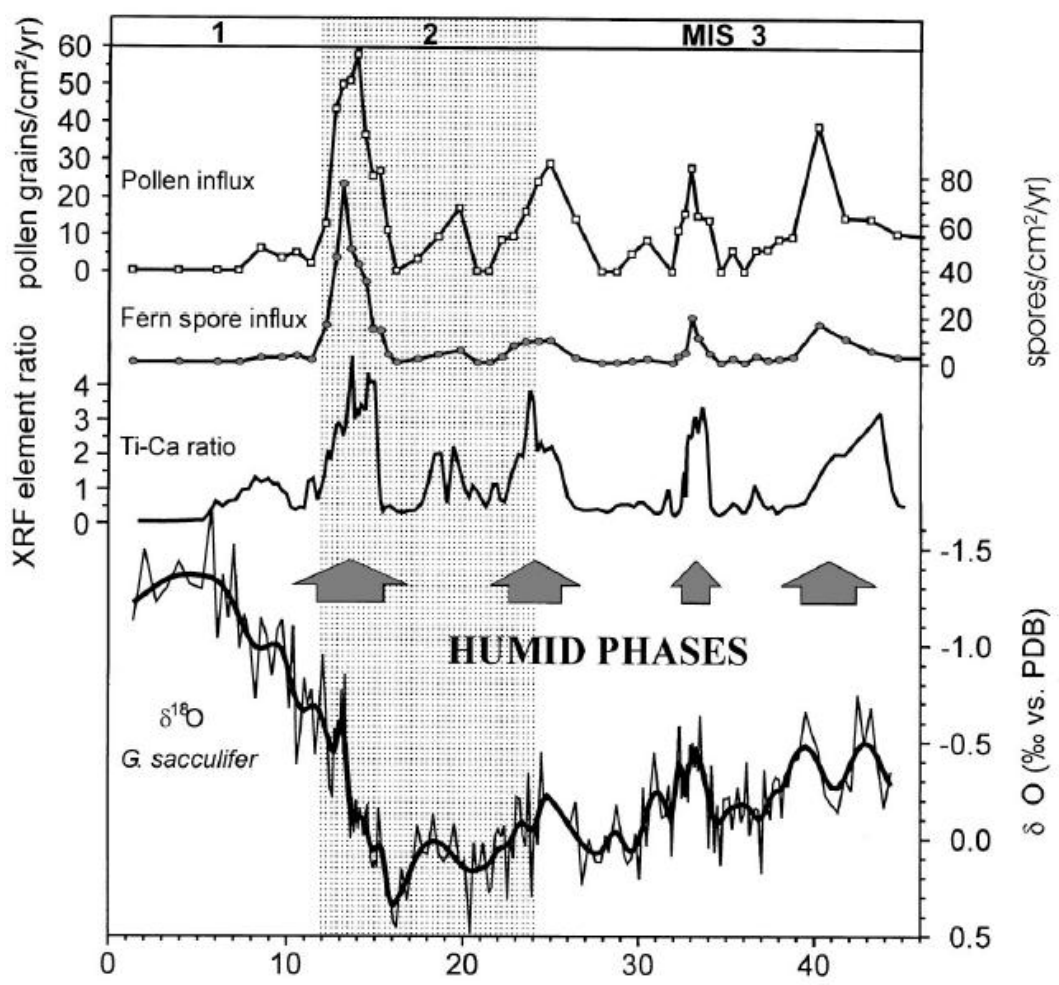

Figura 07: Fases úmidas ocorridas no NE setentrional registrados em sedimentos marinhos. Fonte: Behling et al (2000). 
É provável que este ambiente de savana tenha se mantido entre 24 mil e 18 mil anos A.P., pois as condições climáticas se mantiveram com fases úmidas relativamente rápidas e intercaladas por condições secas (BEHLING et al., 2000). Além disso, a megafauna pleistocênica ainda ocorria nesse período, sendo registados fósseis do Notiomastodon platensis (Ameghino, 1888), datados entre 19.450 - 18.930 anos A.P. no município de Barcelona-RN, e de preguiças gigantes (Eremotherium laurillardi (Lund, 1842)) nos municípios de Currais Novos-RN e Barcelona-RN, datados de 18.850 - 18.580 anos A.P. (DANTAS et al., 2013). Por volta de 15.000 anos A.P., as condições climáticas na área de estudo se tornam úmidas, podendo ter havido no máximo 3 meses secos ao longo do ano (BEHLING et al., 2000), sendo que neste cenário climático houve a expansão da Floresta Tropical Sazonalmente Seca (PRADO; GIBS, 1993).

Para o semiárido do Nordeste Setentrional, é inferido que a cobertura vegetal tenha mudado sua formação, passando de um ambiente com ecossistemas de sanavas e com condições semiáridas intercaladas por momentos úmidos para um ambiente com ecossistemas de florestas montanas nos maciços, expansão das matas de galerias, ambas com características decíduas, estrato herbáceo bem definido ainda ocorrente e condições climáticas mais úmidas que o atual. Para a depressão sertaneja, o porte da vegetação provavelmente era dominado pelo estrato arbóreo com presença de lianas e estratos arbustivo e herbáceo ocorrendo de forma mais densa que o atual. Estas condições paleoambientais e paleoclimáticas persistiram provavelmente até cerca de 11.800 anos A.P. (PRADO; GIBS, 1993; BEHLING et al., 2000). O último registro da megafauna pleistocênica para a região era de um mamífero de pasto, o Toxodonte (Toxodon platensis (Owen, 1840)), encontrado no município de Rui Barbosa-RN e datado de 12.720 - 12.560 anos A.P. (DANTAS et al., 2013).

Por volta de 11 mil anos A.P., as condições climáticas semiáridas retornaram, sendo mais frio e seco que o clima semiárido atual, tal retorno deste paleoclima pode estar ligado ao evento Younger Dryas (BEHLING et al., 2000; MUTZENBERG, 2007; AMORIM, 2015). A provável resposta da cobertura vegetal às características climáticas foi a de perda da densidade de todos os estratos e provável aceleração da erosão dos solos em eventos de pluviosidade com baixa recorrência e alta magnitude. Com base em datação de sedimentos aluviais no município de Carnaúba dos Dantas-RN, Mutzenberg (2007) identificou o retorno de condições úmidas por volta de 7.600 anos A.P. e provável adensamento da cobertura vegetal.

A dinâmica climática da transição Pleistoceno/Holoceno também influenciou na gênese e na dinâmica geomorfológica do Nordeste (RIBEIRO, 2002; SILVA, 2013; AMORIM, 2015). Em estudos sobre dinâmicas climáticas e geomorfológicas no maciço de Baixa Verde-PE, Amorim 
(2015) identificou 07 fases de eventos morfogênicos influenciados pelas mudanças climáticas nos últimos 20 mil anos. Esta dinâmica é corroborada nos estudos de Silva (2013).

Já no Holoceno Médio, por volta de 7 mil anos antes do presente, o clima no semiárido do Nordeste Setentrional passa possivelmente a ter maior influência do El Niño Oscilação Sul (ENOS), que eram mais duradouros que os atuais eventos ENOS (MARTIN et al., 1993; AMORIM, 2015). Com as estações secas mais prolongadas na região, é possível que tenha havido aumento da dissecação de solos da região com a volta das estações chuvosas. Devido às características xerofíticas e caducifólias da cobertura vegetal, é provável que não tenha havido grandes alterações na fisionomia da mesma, que do Holoceno Médio até meados do século XVII, poderia ter fisionomia arbóreo-arbustiva para todo o semiárido, sendo o estrato arbustivo dominante na depressão sertaneja, onde também poderia ter havido presença do estrato arbóreo aliado a lianas. Já nos maciços e inselbergs, o estrato arbóreo juntamente com trepadeiras lenhosas era dominante (atualmente, em muitos desses relevos, este estrato ainda é dominante).

Antes e durante o início da ocupação dos colonos na área de estudo, o evento climático conhecido como a Pequena Idade do Gelo (1700 - 200 anos A.P.) rebaixou as temperaturas médias em todo o planeta, sendo que suas influências climáticas no Nordeste do Brasil foram registradas por Amorim (2015). Este evento climático provavelmente produziu condições mais secas que as atuais, podendo ter levado a uma aumento das taxas de remobilização dos solos em eventos pluviométricos mais intensos.

Após a chegada dos colonos no semiárido do Nordeste Setentrional, por volta do século XVII, a fisionomia da Caatinga passa então a ser alterada até atingir a sua atual fisionomia que em muito se assemelha a uma savana, sendo classificada, principalmente na depressão sertaneja (unidade geomorfológica primeiramente ocupada) como Savana-Estépica Gramíneo-Lenhosa (VELOSO, 1991; IBGE, 1992; IBGE, 2012). Além disso, o evento ENOS passa a ser mais atuante, e consequentemente, os seus efeitos sobre a cobertura vegetal e sobre a remobilização das coberturas pedogenéticas passam a ser mais intensos. Tanto a Pequena Idade do Gelo quanto o ENOS são registrados como fases climáticas que influenciaram a dinâmica geomorfológica no maciço de Baixa Verde-PE (AMORIM, 2015).

Em mais de três séculos de ocupação, os componentes lenhosos da Caatinga sempre apresentaram usos, sendo que durante a ocupação e estabelecimento dos colonos, o estrato arbóreo foi amplamente utilizado na edificação de casas e fazendas (FEIJÓ, 2002). Na edificação das residências empregavam-se vegetais nativos com caules resistentes, tais como a Aroeira (Myracrodruon urundeuva (Allemão)), o Angico (Anadenanthera colubrina (Vell.)), a Craibeira (Tabebuia aurea (Silva Manso) Benth. \& Hook. f ex S. Moore), a Braúna (Schinopsis 
brasiliensis (Engl. 1876)), o Brejuí (Myroxylon peruiferum L. f.) e o Pereiro (Aspidosperma pyrifolium (Mart. \& Zucc.) (FEIJÓ, 2002). A seguir, a Figura 08 mostra a cobertura de uma fazenda na qual foram empregadas duas espécies vegetais em sua estruturação: a Carnaúba (Copernicia prunifera (Mill.) H.E.Moore) e o Brejuí (Myroxylon peruiferum L. f.). Além de usos na edificação das residências, a vegetação era também usada para a confecção de utensílios domésticos, como o pilão, que é feito do caule da Aroeira (Myracrodruon urundeuva (Allemão)) (Figura 09).

No caso do pilão, a sua ocorrência é comum no semiárido, sendo encontrado com facilidade em comunidades rurais mais tradicionais e em antigas fazendas, o que permite dizer que a sua matéria prima, a Aroeira (Myracrodruon urundeuva (Allemão)) foi mais abundante no semiárido do Nordeste Setentrional. A mesma interpretação pode ser feita com relação aos vegetais cujo seus caules foram usados na construção de residências, já que não eram empregados só em edificações da zona rural, mas também em cidades já existentes na época (FEIJÓ, 2002).

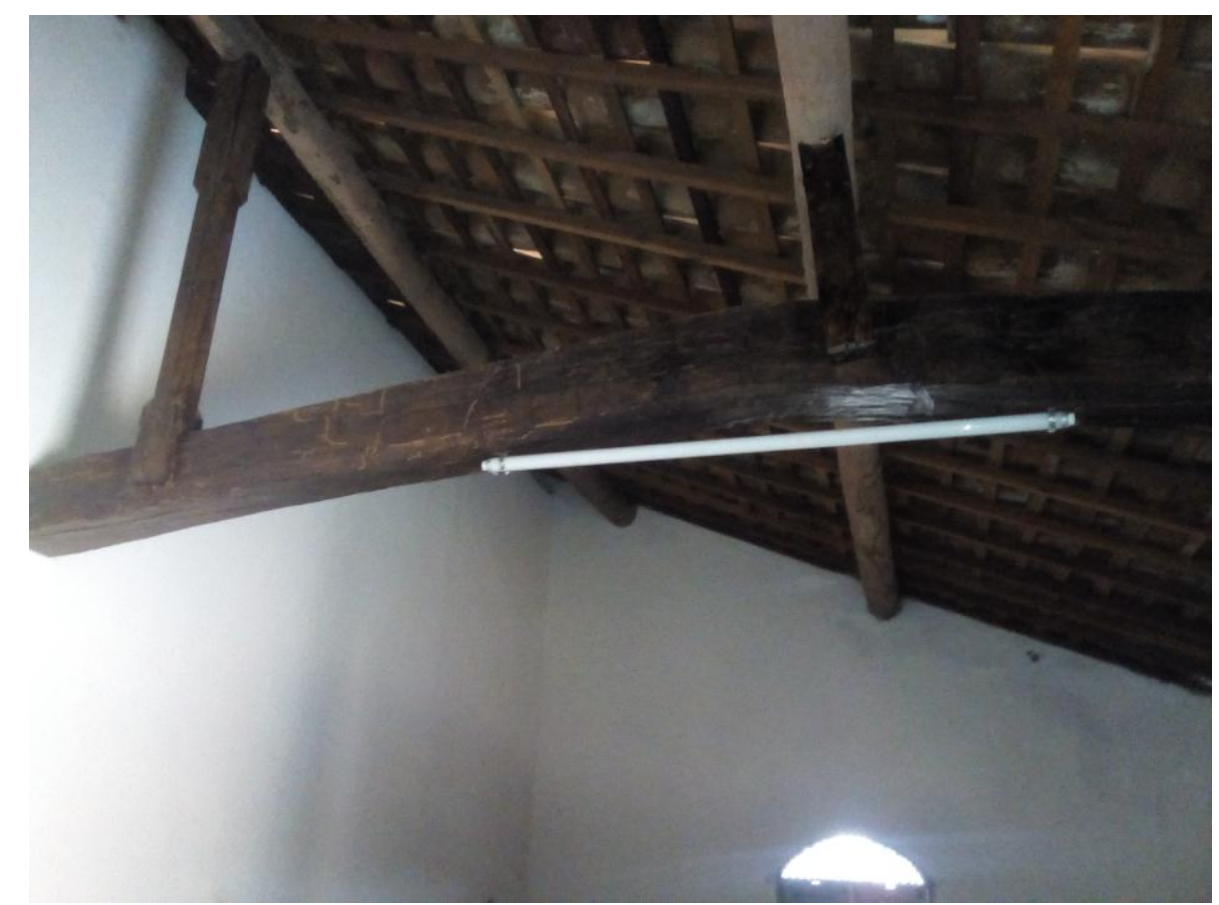

Figura 08: Caule do Myroxylon peruiferum (L. f.) em primeiro plano (juntamente com a lâmpada) e o caule roliço da Copernicia prunifera (Mill.) H.E.Moore, ao fundo. Fonte: Acervo dos autores. 


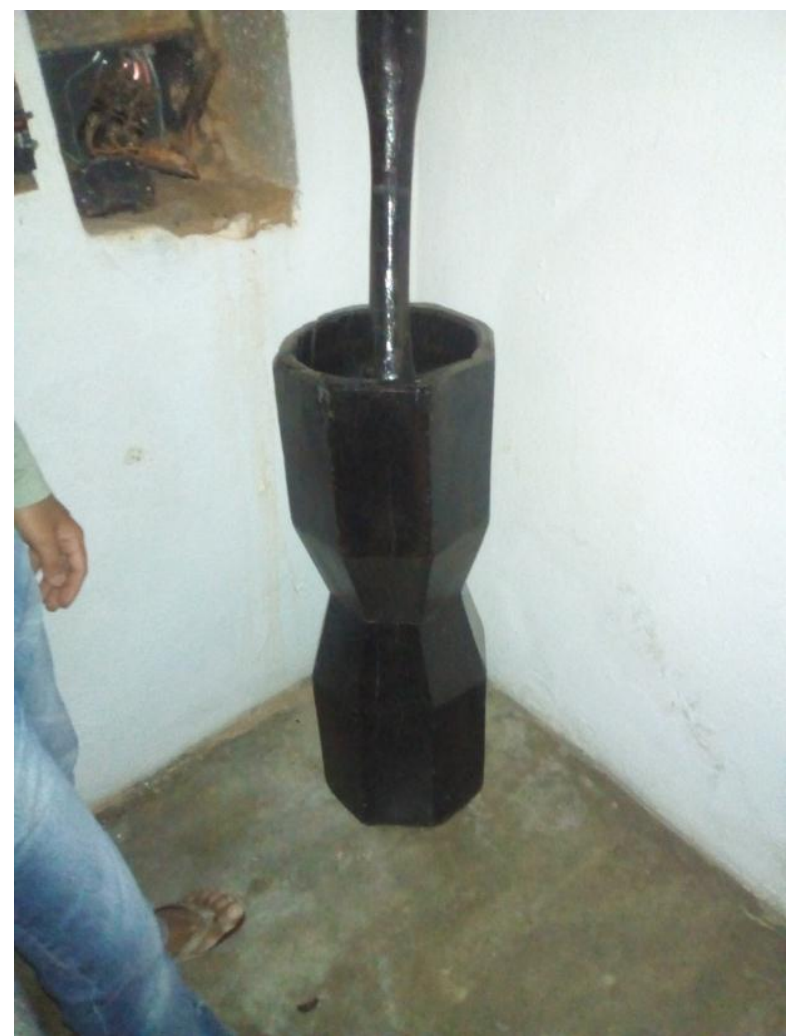

Figura 09: Caule da Myracrodruon urundeuva (Allemão) convertida em um pilão. Fonte: Acervo dos autores.

\section{CONSIDERAÇÕES FINAIS}

As condições paleoambientais do semiárido do Nordeste Setentrional permitem inferir que a fisionomia da Caatinga oscilou entre savanas com condições de manter uma megafauna pleistocênica e fisionomias florestais (a fisionomia da FTSS não deve ser associada a fisionomia das florestas tropicais). Antes do início de sua alteração pela ação humana, a cobertura vegetal tinha marcante presença de indivíduos arbóreos, que atualmente se encontram confinados em alguns maciços e inselbergs em meio à depressão sertaneja. Pode-se concluir que a atual fisionomia da vegetação é mais resultado de antropização do que por influências ambientais, sendo que tal conclusão reside no fato que componentes arbóreos foram largamente usados até o seu quase desaparecimento.

Outros fatores a serem considerados são dissecação generalizada dos solos, tornando o ambiente menos favorável para a evolução dos estágios serais e colonização de espécies arbóreas, e as práticas agropecuárias, as quais exigiam a retirada da cobertura vegetal para plantio e em alguns casos, pastagem dos rebanhos (a retirada da vegetação era - e ainda é - feita por meio de queimadas). 


\section{REFERÊNCIAS}

AB'SÁBER, A. N. The paleoclimate and paleoecology of Brazilian Amazonia. IN: PRANCE, G.T. (Ed.). Biological diversification in the Tropics. Nova York: University Press, 1982. p. 41-59.

ADAMS, J.; MASLIN, M.; THOMAS, E. Sudden climate transitions during the Quaternary. Progress in Physical Geography, v. 23, n. 1, p. 1-36, 1999.

AMORIM, I. L.; SAMPAIO, E. V. S. B.; ARAÚJO, E. L. Flora e estrutura da vegetação arbustivoarbórea de uma área de caatinga do Seridó, RN, Brasil. Acta botânica brasílica, v. 19, p. 615-623, 2005.

AMORIM, I. L.; SAMPAIO, E. V. S. B.; ARAÚJO, E. L. Fenologia de espécies lenhosas da caatinga do Seridó, RN. Revista Árvore, v. 33, n. 3, 2009.

AMORIM, R. F. Integração entre dinâmicas geomorfológicas multitemporais no planalto da Borborema, semiárido do NE do Brasil. Tese de doutorado apresentado ao Programa de Pósgraduação em Geografia da UFPE. 2015. 193 f.

AMORIM, R. F.; CORRÊA, A. C. B.; SILVA, D. G. S. Tempo e magnitude nos processos geomorfológicos. Geografia, v. 41, n. 1, p. 17-31, 2016.

BEHLING, H.; ARZ, H. W.; PÄTZOLD, J.; WEFER, G. Late Quaternary vegetational and climate dynamics in northeastern Brazil, inferences from marine core GeoB 3104-1. Quaternary Science Reviews, v. 19, n. 10, p. 981-994, 2000.

BROWN, J. H.; LOMOLINO, M. V. Biogeografia, São Paulo: FUNPEC-Editora, 2006.

CAETANO, S., PRADO, D., PENNINGTON, R. T., BECK, S., OLIVEIRA-FILHO, A., SPICHIGER, R., NACIRI, Y. The history of seasonally dry tropical forests in eastern South America: inferences from the genetic structure of the tree Astronium urundeuva (Anacardiaceae). Molecular Ecology, v. 17, n. 13, p. 3147-3159, 2008.

DANTAS, M. A. T.; DUTRA, R. P.; CHERKINSKY, A.; FORTIER, D. C.; KAMINO, L. H. Y.; COZZUOL, M. A.; RIBEIRO, A. S.; VIEIRA, F. S. Paleoecology and radiocarbon dating of the Pleistocene megafauna of the Brazilian Intertropical Region. Quaternary Research, v. 79, n. 1, p. 61-65, 2013.

DANTAS, M. A. T.; XAVIER, M. C. T.; MELO FRANÇA, L.; COZZUOL, M. A.; SOUZA RIBEIRO, A.; FIGUEIREDO, A. M. G.; KINOSHITA, A.; BAFFA, O. A review of the time scale and potential geographic distribution of Notiomastodon platensis (Ameghino, 1888) in the late Pleistocene of South America. Quaternary international, v. 317, p. 73-79, $2013 \mathrm{a}$. 
FEIJÓ, P. H. F. A arquitetura tradicional de acari no século XIX: estudo comparativo entre a casa-grande de fazenda e a casa urbana. Dissertação de mestrado apresentado ao Programa de Pós Graduação em Arquitetura da Universidade Federal do Rio Grande do Norte. 2002. 175 f.

HAFFER, J. Speciation in Amazonian forest birds. Science, v. 165, n. 3889, p. 131-137, 1969.

IBGE. Instituto Brasileiro de Geografia e Estatística. Manual Técnico da Vegetação Brasileira. 2 ed. Rio de Janeiro: IBGE, 2012. p. 275.

IBGE. Instituto Brasileiro de Geografia e Estatística. Manual Técnico da Vegetação Brasileira. Rio de Janeiro: IBGE, 1992. 92 p.

KINOSHITA, A.; FRANCA, A. M.; ALMEIDA; J. A. C.; FIGUEIREDO, A. M.; NICOLUCCI, P.; GRAEFF, C. O.; BAFFA, O. ESR dating at $\mathrm{K}$ and $\mathrm{X}$ band of northeastern Brazilian megafauna. Applied Radiation and Isotopes, v. 62, n. 2, p. 225-229, 2005.

MAIA, R. P.; AMARAL, R. F.; PRAXEDES, S. Geomorfologia do Rio Grande do Norte In: Albano, G. P; FERREIRA, L. S; ALVES, A. M. (Orgs.). Capítulos de Geografia do Rio Grande do Norte. Natal: Manimbu, 2013. p. 20-59.

MAIA, R. P. BEZERRA, F. H. R. Tópicos de geomorfologia estrutural: Nordeste brasileiro. Fortaleza: Edições UFC, 2014. 124 p.

MARTIN, L.; FOURNIER, M.; MOURGUIART, P.; SIFEDDINE, A.; TURCQ, B.; FLEXOR, J. M.; ABSY, M. L. Southern Oscillation signal in South American palaeoclimatic data of the last 7000 years. Quaternary Research, v. 39, n. 3, p. 338-346, 1993.

MUTZENBERG, D. S. Gênese e ocupação pré-histórica do Sítio Aqueológico Pedra do Alexandre: uma abordagem a partir da caracterização paleoambiental do vale do Rio CarnaúbaRN. Dissertação de mestrado apresentado ao Programa de Pós Graduação em Arqueologia da UFPE. 2007. $142 \mathrm{f}$.

NETO, M. C. P.; SILVA, N. M. Relevos residuais (maciços, inselbergues e cristas) como refúgios da biodiversidade no Seridó Potiguar. Revista Geonorte, v. 3, n. 4, p. 262-273, 2012.

NETO, M. C. P.; FERNANDES, E. Instabilidade emergente e aspectos de degradação ambiental da bacia hidrográfica do rio Seridó (RN/PB-Brasil). Revista de Geografia (Recife), v. 33, n. 1, 2016.

OLIVEIRA, P. E.; PESSENDA, L. C. R.; BARRETO, A. M. F.; OLIVEIRA, E. V.; SANTOS, J. C. Paleoclimas da caatinga brasileira durante o Quaternário tardio. IN: CARVALHO, I. S.; JUDITE GARCIA, M.; LANA, C. C.; STROHSCHOEN JR, O. (Eds). Paleontologia: Cenários de vida Paleoclimas. Rio de Janeiro: Editora Interciência, 2014. p. 501 - 516. 
PENNINGTON, R. T.; PRADO, D. E.; PENDRY, C. A. Neotropical seasonally dry forests and Quaternary vegetation changes. Journal of Biogeography, v. 27, n. 2, p. 261-273, 2000.

PENNINGTON, R. T.; LAVIN, M.; PRADO, D. E.; PENDRY, C. A.; PELL, S. K.; BUTTERWORTH, C. A. Historical climate change and speciation: neotropical seasonally dry forest plants show patterns of both Tertiary and Quaternary diversification. Philosophical Transactions of the Royal Society of London: Biological Sciences, v. 359, n. 1443, p. 515-538, 2004.

PETIT, J. R..; JOUZEL, J.; RAYNAUD, D. N.; BARKOV, I.; BARNOLA, J. M.; BASILE, I.; BENDER, M.; CHAPPELLAZ, J.; DAVIS, M.; DELAYGUE, G.; DELMOTTE, M.; KOTLYAKOV, V. M.; LEGRAND, M.; LIPENKOV, V. Y.; LORIUS, C.; PÉPIN, L.; RITZ, C.; SALTZMANK, E.; STIEVENARD, M. Climate and atmospheric history of the past 420,000 years from the Vostok ice core, Antarctica. Nature, v. 399, n. 6735, p. 429-436, 1999.

PRADO, D. E.; GIBBS, P. E. Patterns of species distributions in the dry seasonal forests of South America. Annals of the Missouri Botanical Garden, p. 902-927, 1993.

RIBEIRO, A. S. Dinâmica paleoambiental da vegetação e clima durante o Quaternário tardio em domınios da mata Atlântica, brejo do semiárido e cerrado nordestinos, utilizando isótopos do carbono da matéria orgânica do solo e das plantas. Tese de doutorado apresentado ao Programa de Pós Graduação do Centro de Energia Nuclear, USP. 2002. $193 f$.

RODAL, M. J. N.; BARBOSA, M. R. V.; THOMAS, W. W. Do the seasonal forests in northeastern Brazil represent a single floristic unit? Brazilian Journal of Biology, v. 68, n. 3, p. 467-475, 2008.

SANTANA, J. A. S.; VIEIRA, F. A.; PACHECO, M. V.; OLIVEIRA, P. R. S. Padrão de distribuição e estrutura diamétrica de Caesalpinia pyramidalis Tul.(Catingueira) na Caatinga do Seridó. Revista de biologia e ciências da terra, v. 11, n. 1, 2011.

SANTOS, C. A. G.; SUZUKI, K.; WATANABE, M.; SRINIVASAN, V. S. Influência do tipo da cobertura vegetal sobre a erosão no semiárido paraibano. Revista Brasileira de Engenharia Agrícola e Ambiental, v. 4, n. 1, p. 92-96, 2000.

SILVA, D. G. Reconstrução da Dinâmica Geomorfológica do Semiárido Brasileiro no Quaternário Superior a Partir de uma Abordagem Multiproxy. Tese de doutorado apresentado ao Programa de Pós-graduação em Geografia da UFPE. 2013. 277 f.

SUGUIO, K. Geologia do Quaternário e mudanças ambientais. São Paulo: Oficina de Textos, 2010. 408 p.

VAN DER HAMMEN, T.; ABSY, M. L. Amazonia during the last glacial. Palaeogeography, palaeoclimatology, palaeoecology, v. 109, n. 2, p. 247-261, 1994. 
VELOSO, H. P. Classificação da vegetação brasileira adaptada a um sistema universal. Rio de Janeiro: IBGE, 1991. 124 p.

\section{AGRADECIMENTOS}

Ao Programa de Pós-Graduação em Geografia URFN - PPGe, ao Grupo de Pesquisa em Geoecologia e Biogeografia de Ambientes Tropicais - TRÓPIKOS, e ao Laboratório Multiusuário de Monitoramento Ambiental - LAMMA.

Recebido em: 15/08/2018

Aceite para publicação em: 05/11/2018 